\title{
Microstructural Study on Kirkendall Void Formation in Sn-Containing/Cu Solder Joints During Solid-State Aging
}

\author{
Zhi-Quan Liu, ${ }^{*}$ Pan-Ju Shang, Feifei Tan, and Douxing Li \\ Shenyang National Laboratory for Materials Science, Institute of Metal Research, Chinese Academy of Sciences, \\ 72 Wenhua Road, Shenyang, Liaoning 110016, China
}

\begin{abstract}
Kirkendall void formation at the solder/metallization interface is an important reliability concern for $\mathrm{Cu}$ conductors and under-bump metallization in microelectronic packaging industry, whose mechanism is still hard to be understood for different individual cases. In the present work, two typical solder/Cu-diffusing couples, eutectic $\mathrm{SnIn} / \mathrm{Cu}$ and $\mathrm{SnBi} / \mathrm{Cu}$, were studied by scanning/transmission electron microscopy to investigate the microstructural evolution and voiding process after soldering and then solid-state aging. It was concluded that Kirkendall voids formed between two sublayers within $\mathrm{Cu}_{2}(\mathrm{In}, \mathrm{Sn})$ phase in eutectic $\mathrm{SnIn} / \mathrm{Cu}$ solder joint, whereas they appeared at the $\mathrm{Cu}_{3} \mathrm{Sn} / \mathrm{Cu}$ interface or within $\mathrm{Cu}_{3} \mathrm{Sn}$ for eutectic $\mathrm{SnBi} / \mathrm{Cu}$ solder joint. Besides the effect of impurity elements, the morphological difference within one intermetallic compound layer could change the diffusing rates of reactive species, hence resulting in void formation in the reaction zone.
\end{abstract}

Key words: lead-free solder, Kirkendall void, intermetallic compound (IMC), diffusion, interface, transmission electron microscopy (TEM)

\section{INTRODUCTION}

The Kirkendall voids have been widely observed between Sn-containing solders and $\mathrm{Cu}$ substrate during solid-state aging process, such as in $\mathrm{SnPb} / \mathrm{Cu}, \mathrm{SnBi} / \mathrm{Cu}, \mathrm{SnAg} / \mathrm{Cu}$, and $\mathrm{SnAgCu} / \mathrm{Cu}$ solder joints (Zeng et al., 2005; Peng et al., 2007; Kim \& Yu, 2008a; Shang et al., 2008). At present, the mechanism of void formation is widely considered to be due to the Kirkendall effect, which means that the $\mathrm{Cu}$ diffusion is faster than the $\mathrm{Sn}$ diffusion during solid-state aging, resulting in a net vacancy flux of $\mathrm{Cu}$ at the interface of intermetallic compound (IMC) or inside the $\mathrm{Cu}_{3} \mathrm{Sn}$ (Laurila et al., 2005). However, it is still hard to understand the mechanism of void formation for different cases. van Dal et al. (2001) and Paul (2004) have predicted that the Kirkendall planes in a given solid-state diffusion couple need not be unique, which can be multiple, stable, or unstable. Following the theoretical predication, Laurila et al. (2005) reflowed the pure $\mathrm{Sn}$ or pure $\mathrm{SnAgCu}$ solder on oxygen-free high conductive (OFHC) $\mathrm{Cu}$ and then annealed the samples at $398 \mathrm{~K}$ up to $1,000 \mathrm{~h}$ and did not observe any voids using field-emission scanning electron microscope (SEM). Therefore, the void formation in Sn-containing solders and $\mathrm{Cu}$ interface was ascribed to the quality of $\mathrm{Cu}$. Kim \& Yu (2008b) recently designed systematic experiments to check the effects of impurity in $\mathrm{Cu}$ on the void formation during solid-state aging of $\mathrm{Sn}-3.5 \mathrm{Ag}$ solder and four types of $\mathrm{Cu}$ metallizations. The interesting results revealed that (1) no void was found in the joint made of pure $\mathrm{Cu}$ foil; (2) voids distributed uniformly in the matrix of $\mathrm{Cu}_{3} \mathrm{Sn}$ phase in the joint made of electroplated $\mathrm{Cu}$ film without SPS (bis-

() MICROSCOPY SOCIETY OF AMERICA 2013

*Corresponding author. E-mail: zqliu@imr.ac.cn; zhiquanliu@yahoo.com sodium sulfopropyldisulfide, $\mathrm{C}_{6} \mathrm{H}_{12} \mathrm{O}_{6} \mathrm{~S}_{4} \mathrm{Na}_{2}$ ); (3) in the joint made of electroplated $\mathrm{Cu}$ with SPS, voids nucleated and grew at the $\mathrm{Cu} / \mathrm{Cu}_{3} \mathrm{Sn}$ interface because of the $\mathrm{S}$ segregation at the $\mathrm{Cu} / \mathrm{Cu}_{3} \mathrm{Sn}$ interface, which reduced the free-energy barrier for void nucleation and accelerated void formation at the interface. These results are explicit evidences to confirm the influence of the compositions of the end members of the diffusion couple. Besides the residual impurities introduced from the substrate, some ingredients of the solder itself, such as $\mathrm{Bi}$ in eutectic $\mathrm{SnBi}$ solder, can also segregate to the $\mathrm{Cu} / \mathrm{Cu}_{3} \mathrm{Sn}$ interface and accelerate the void formation (Shang et al., 2008).

Most recently, we observed void formation between two different morphological IMCs at the eutectic $\mathrm{SnIn} / \mathrm{Cu}$ solder joint (Shang et al., 2011). It is quite different from the circumstances that occurred at the $\mathrm{Cu} / \mathrm{Cu}_{3} \mathrm{Sn}$ interfaces in $\mathrm{SnBi} / \mathrm{Cu}, \mathrm{SnPb} / \mathrm{Cu}$, or $\mathrm{SnAgCu} / \mathrm{Cu}$ diffusion couples. The motivation of this paper is to elaborate the mechanism of void formation at the SnIn/Cu interface, compared with that induced by impurities from the under-bump metallizations or from solder itself, using transmission electron microscopy (TEM).

\section{Materials and Methods}

The solder alloys used in this study were prepared by melting high-purity $\mathrm{In}, \mathrm{Bi}$, and $\mathrm{Sn}$ into different ingots, and cold rolled into 1-mm-thick foils, and then cut into pieces of size $10 \times 2.5 \mathrm{~mm}^{2}$. The OFHC polycrystalline $\mathrm{Cu}$ was selected as the substrate and then cut by electro-discharge machine into blocks of size $10 \times 2.5 \times 2 \mathrm{~mm}^{3}$. Copper surfaces were grinded and carefully polished using $0.5 \mu \mathrm{m}$ diamond paste, and then rinsed in acetone, methanol alco- 

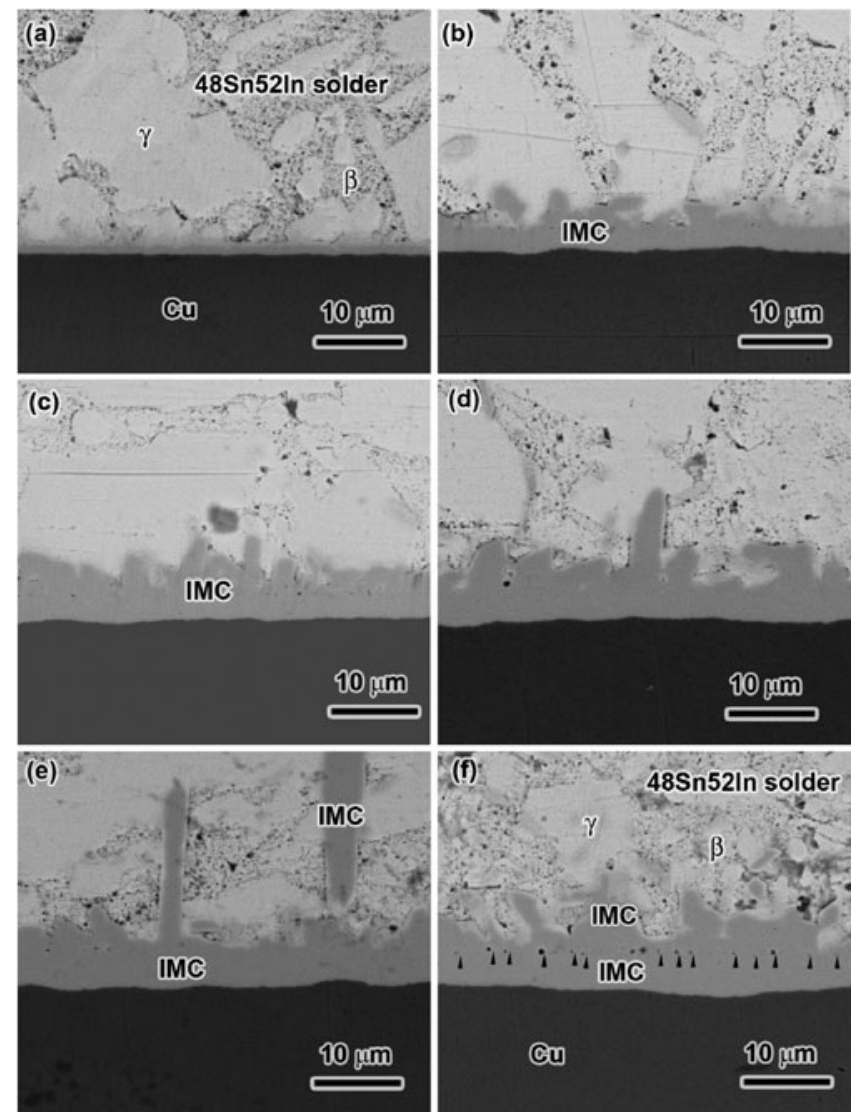

Figure 1. Cross-sectional SEM images of eutectic SnIn/Cu solder joint after (a) reflowing at $433 \mathrm{~K}$ for $5 \mathrm{~s}$, and then solid-state aging at $373 \mathrm{~K}$ for (b) 1 day, (c) 2 days, (d) 4 days, (e) 5 days, and (f) 6 days. SEM, scanning electron microscope; IMC, intermetallic compound.

hol, and distilled water in an ultrasonic bath. Two copper sheets were soldered together with the eutectic SnIn or SnBi alloys to form a copper-solder sandwich, in which several brass wires with a diameter of $50 \mu \mathrm{m}$ were placed inbetween two copper sheets to control the gap thickness. Solder reflowing of SnIn joints was performed at the temperature of $433 \mathrm{~K}$ for $5 \mathrm{~s}$, and then solid-state aged at $373 \mathrm{~K}$ for different days. For comparison, eutectic $\mathrm{SnBi} / \mathrm{Cu}$ solder joints were reflowed at $443 \mathrm{~K}$ for $5 \mathrm{~s}$ and aged at $393 \mathrm{~K}$ up to 2 days.

The cross-sectional interface samples for microstructural analysis were prepared with the standard method. SEM observations were carried out on an FEI Quanta 600 SEM equipped with an Oxford Link ISIS energy-dispersive $\mathrm{X}$-ray spectroscopy (EDS) system. An FEI Tecnai F30 electron microscope was used to carry out TEM/scanning transmission electron microscopy (STEM) observations at an accelerating voltage of $300 \mathrm{kV}$.

\section{Results}

The typical interfacial images of the eutectic SnIn/Cu solder joint after reflowing and solid-state aging were shown in Figure 1. After reflowing at $433 \mathrm{~K}$ for $5 \mathrm{~s}$, a thin uniform

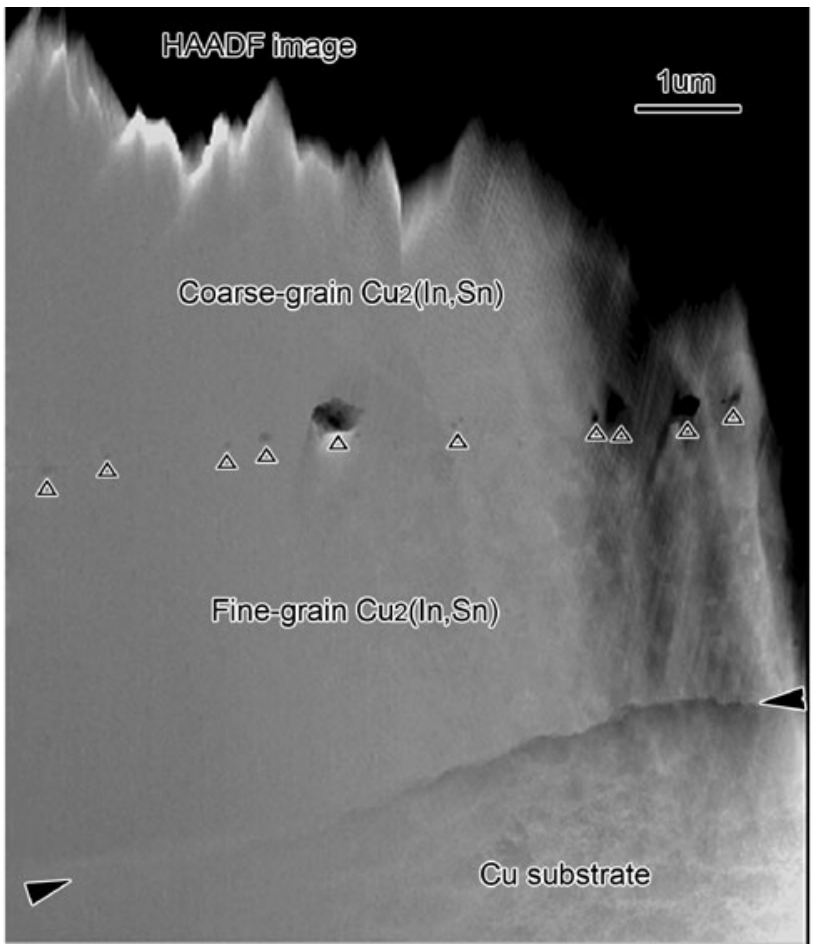

Figure 2. Low-magnification HAADF-STEM image showing the interfacial microstructure of eutectic $\mathrm{SnIn} / \mathrm{Cu}$ after solid-state aging for 7 days at $373 \mathrm{~K}$. The IMC/Cu interface was marked by black arrowheads, whereas white arrow heads indicate the voids within the IMC layer. HAADF, high-angle annular dark-field; STEM, scanning transmission electron microscopy; IMC, intermetallic compound.

IMC with a thickness of $1-2 \mu \mathrm{m}$ was formed at the interface of eutectic SnIn/Cu as shown in Figure 1a. In the following solid-state aging process, the thickness of IMC increased quickly at the initial stage. It grew to more than $4 \mu \mathrm{m}$ after only 1 day of aging in Figure 1b, and extended into the solder side gradually with a rod-like morphology after 2 days (see Figs. 1c-1e). However, in the late stage, the increase of IMC thickness was not distinct owing to the depletion of IMC from the interface into the solder. Six days later, some voids appeared inside the IMC layer, as indicated by arrowheads in Figure 1f, but no void was observed at the IMC/Cu interface. Although the size of voids is not uniform, they locate at the same plane. This was further verified by our high-angle annular dark-field-STEM (HAADF-STEM) observations. Figure 2 shows the typical low-magnification HAADF-STEM image of the sample that was solid-state aged for 7 days, and the voids ranging from tens to hundreds of nanometers (indicated by white arrowheads) were found within the IMC layer. However, the interface between IMC and $\mathrm{Cu}$ marked with black arrowheads in Figure 2 is completely void free, which is in complete accordance with SEM observations. It has been revealed that there was only one kind of IMC, $\mathrm{Cu}_{2}(\mathrm{In}, \mathrm{Sn})$, at the interface of eutectic $\mathrm{SnIn/Cu}$ solder joint after reflowing, which has two kinds of grain morphologies: a finegrain sublayer at the $\mathrm{Cu}$ side and a coarse-grain sublayer at 

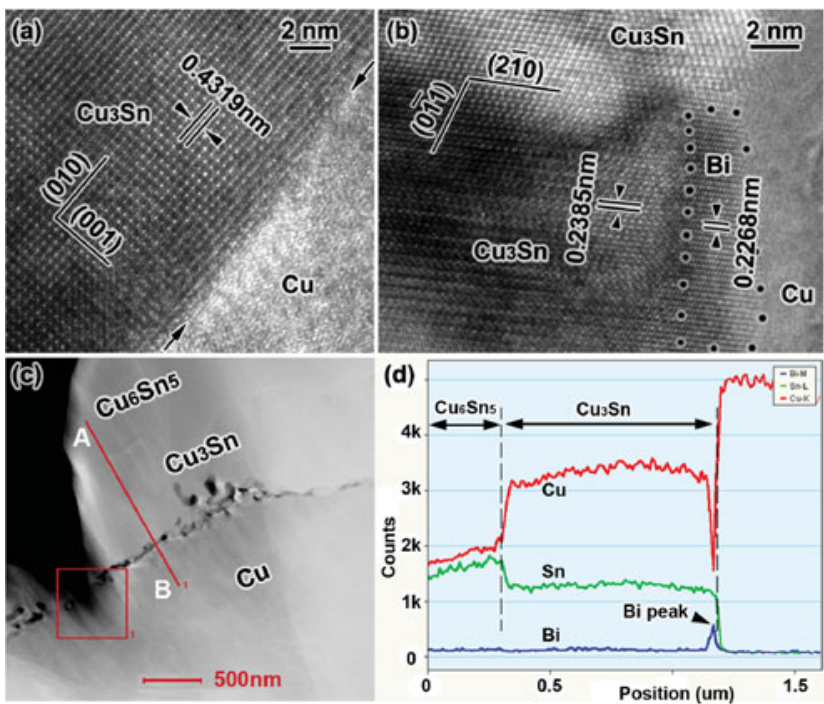

Figure 3. TEM images of $\mathrm{Cu}_{3} \mathrm{Sn} / \mathrm{Cu}$ interface in eutectic $\mathrm{SnBi} / \mathrm{Cu}$ solder joint after (a) reflowing at $443 \mathrm{~K}$ for $5 \mathrm{~s}$, and (b) solid-state aging at $393 \mathrm{~K}$ for 1 day, as well as (c) interfacial HAADF image after solid-state aging at $393 \mathrm{~K}$ for 2 days, and (d) the corresponding EDS line scan inside the IMC layer. TEM, transmission electron microscopy; HAADF, high-angle annular dark-field; EDS, energy-dispersive X-ray spectroscopy; IMC, intermetallic compound.

the solder side (Shang et al., 2011). Our TEM observations confirmed that the voids formed exactly at the interface between coarse-grain and fine-grain $\mathrm{Cu}_{2}(\mathrm{In}, \mathrm{Sn})$ sublayers (see Fig. 2).

The interfacial microstructural change of the eutectic $\mathrm{SnBi} / \mathrm{Cu}$ solder joint was also investigated. The $\mathrm{Cu} / \mathrm{Cu}_{3} \mathrm{Sn}$ interface viewed along the $\mathrm{Cu}_{3} \mathrm{Sn}$ [100] zone axis is shown in Figure 3a, where the interface (indicated by arrows) is relatively smooth and no void or atomic segregation took place after a short time of reflowing. After 1 day of aging at $393 \mathrm{~K}$, voids began to appear at the $\mathrm{Cu} / \mathrm{Cu}_{3} \mathrm{Sn}$ interface, and $\mathrm{Bi}$ segregation was also observed. Figure $3 \mathrm{~b}$ shows a high-resolution TEM (HRTEM) image of a segregated Bi particle (about $5 \mathrm{~nm}$ ) at the $\mathrm{Cu}_{3} \mathrm{Sn} / \mathrm{Cu}$ interface. The crystallographic analyses on the HRTEM image revealed that there is a special crystallographic relationship between $\mathrm{Cu}_{3} \mathrm{Sn}$ and $\mathrm{Bi}$ particle with a small lattice misfit of about $5 \%:(2 \overline{1} 0)_{\mathrm{Cu}_{3} \mathrm{Sn}} / /(\overline{1} \overline{1} 0)_{\mathrm{Bi}}$ and $[122]_{\mathrm{Cu}_{3} \mathrm{Sn}} / /[\overline{7} 71]_{\mathrm{Bi}}$, in which $\mathrm{Cu}_{3} \mathrm{Sn}$ has a basic orthorhombic lattice with dimensions of $a=0.5514 \mathrm{~nm}, b=0.4765 \mathrm{~nm}$, and $c=0.4329 \mathrm{~nm}$, whereas Bi has a rhombohedral lattice with dimensions of $a=b=$ $0.4547 \mathrm{~nm}$ and $c=1.186 \mathrm{~nm}$. This gives explicit evidence that $\mathrm{Bi}$ precipitates from the $\mathrm{Cu}_{3} \mathrm{Sn}$ phase to form segregated particles at the interface. Moreover, it is clear that the Bi segregation takes place before the void formation, because the boundary of the initial Bi particle is void free in Figure 3b. After 2 days of solid-state aging at $393 \mathrm{~K}$, the interface in eutectic $\mathrm{SnBi} / \mathrm{Cu}$ solder joint became highly porous, as shown in Figure $3 \mathrm{c}$. The voids formed not only at the $\mathrm{Cu}_{3} \mathrm{Sn} / \mathrm{Cu}$ interface but also within the $\mathrm{Cu}_{3} \mathrm{Sn}$ phase, whereas at the $\mathrm{Cu}_{6} \mathrm{Sn}_{5} / \mathrm{Cu}_{3} \mathrm{Sn}$ interface there was no void even after a long duration of aging. The extensive TEM observations revealed that two different morphological $\mathrm{Cu}_{3} \mathrm{Sn}$ layers were formed between $\mathrm{Cu}_{6} \mathrm{Sn}_{5}$ and $\mathrm{Cu}$ during solidstate aging, a columnar grain layer at the $\mathrm{Cu}_{6} \mathrm{Sn}_{5}$ side and an equiaxed grain layer at the $\mathrm{Cu}$ side (Shang et al., 2009a, 2009b). Basing on Paul's prediction using the physicochemical approach, a Kirkendall plane in a diffusion zone should always be accompanied by a sharp change in morphology within a phase layer (Paul et al., 2004). Therefore, it is predicted that the Kirkendall plane within the $\mathrm{Cu}_{3} \mathrm{Sn}$ layer in eutectic $\mathrm{SnBi} / \mathrm{Cu}$ corresponds to the interface between the columnar grain sublayer and equiaxed grain sublayer, which could explain the void formation within the $\mathrm{Cu}_{3} \mathrm{Sn}$ layer very well. On the other hand, the EDS line scan across the IMC/Cu interface revealed that a strong Bi peak appeared at the $\mathrm{Cu}_{3} \mathrm{Sn} / \mathrm{Cu}$ interface on the $\mathrm{Cu}_{3} \mathrm{Sn}$ side, as shown in Figure 3d. Thus, the segregated Bi particles at the $\mathrm{Cu} / \mathrm{Cu}_{3} \mathrm{Sn}$ interface can act as a barrier for $\mathrm{Cu}$ diffusion and result in the void formation at the $\mathrm{Cu}_{3} \mathrm{Sn} / \mathrm{Cu}$ interface.

\section{DISCUSSION}

On comparing the microstructural changes in both eutectic $\mathrm{SnIn} / \mathrm{Cu}$ and $\mathrm{SnBi} / \mathrm{Cu}$ solder joints, although the locations of void formation are different, one common feature of both diffusion couple system is that the void formation is always accompanied by a sharp morphological change within the same IMC layer. It could be a common phenomenon that occurs in many solder/UBM joints, such as Sn-3.5Ag/ $\mathrm{Ni}-\mathrm{P}$ solder joint and so on (He et al., 2004). To understand its origin of void formation, atomic diffusion of reactive species across the interface of morphological change within an IMC layer should be considered, together with the growth of IMC itself. Driven by the concentration gradient in the solder joint, $\mathrm{Cu}$ and $\mathrm{Sn}$ atoms should diffuse toward solder and substrate sides, respectively, during solid-state aging process. However, the diffusing rates of reactive atoms in coarse-grain and fine-grain $\mathrm{Cu}_{2}(\mathrm{In}, \mathrm{Sn})$ sublayer should be different considering the contribution of grain boundaries. It is well known that the effective interdiffusion coefficient, $D_{\text {eff }}$, may be expressed as follows (Bader et al., 1995):

$$
D_{\text {eff }}=D+a(2 \delta / d) D_{b}
$$

where $d$ is the average grain size, $\delta$ is the thickness of the grain boundary, $a$ is a shape constant $(\approx 1), D$ is the volume diffusion coefficient, and $D_{b}$ is the grain boundary diffusion coefficient. As the fine-grain sublayer has a smaller grain size $(d)$ and more grain boundaries $(\delta)$, the atomic diffusing rate in fine-grain $\mathrm{Cu}_{2}(\mathrm{In}, \mathrm{Sn})$ sublayer should be faster than that in the coarse-grain $\mathrm{Cu}_{2}(\mathrm{In}, \mathrm{Sn})$ layer. Considering the diffusion of Sn (or In) atoms, when they go through the coarse-grain sublayer and arrive at the interface between coarse-grain and fine-grain sublayers, they will diffuse away faster through fine-grain sublayer to the $\mathrm{Cu}$ substrate side to form new $\mathrm{Cu}_{2}(\mathrm{In}, \mathrm{Sn})$ grains. Therefore, vacancies will be left at the interior interface of $\mathrm{Cu}_{2}(\mathrm{In}, \mathrm{Sn})$. Although these vacancies could be consumed by $\mathrm{Cu}$ atoms diffused from substrate, it is believed that the consumption is not 
enough, because $\mathrm{Cu}$ can diffuse through the IMC layer easily, and more $\mathrm{Cu}$ atoms are needed at the solder side to form coarse $\mathrm{Cu}_{2}(\mathrm{In}, \mathrm{Sn})$ grain [the atomic ratio of $\mathrm{Cu}: \mathrm{Sn}$ (or In) in the compound is 2:1]. As a result, more vacancies were left at the interior interface between $\mathrm{Cu}_{2}(\mathrm{In}, \mathrm{Sn})$ sublayers accompanying the growth of IMC. These vacancies will increase and coalesce during solid-state aging to form voids finally, which is also due to Kirkendall effect considering the different diffusion rates of Sn (or In) atoms in different $\mathrm{Cu}_{2}(\mathrm{In}, \mathrm{Sn})$ sublayers. This proposed mechanism of void formation is different from the impurity-induced void.

\section{CONCLUSIONS}

A compared experimental study of void formation in the eutectic $\mathrm{SnIn} / \mathrm{Cu}$ and $\mathrm{SnBi} / \mathrm{Cu}$ solder joints was conducted by SEM and TEM/STEM observations. At the eutectic $\mathrm{SnIn} / \mathrm{Cu}$ interface, $\mathrm{Cu}_{2}(\mathrm{In}, \mathrm{Sn})$ was formed with two different morphologies during reflowing and solid-state aging. Kirkendall voids appeared exactly at the interface between coarse-grain and fine-grain sublayers. For the eutectic $\mathrm{SnBi} / \mathrm{Cu}$ interface, voids were situated both inside the $\mathrm{Cu}_{3} \mathrm{Sn}$ phase (between columnar and equiaxed grain sublayers) and at the exact $\mathrm{Cu}_{3} \mathrm{Sn} / \mathrm{Cu}$ interface. It was found that if we excluded the impurity-induced voids at the $\mathrm{Cu}_{3} \mathrm{Sn} / \mathrm{Cu}$ interface, the void formation was always accompanied by an obvious morphological change, which results in the different diffusing rate of reactive species in different sublayers, and hence leads to the formation of voids at the interface between different morphological sublayers within the same IMC phase layer.

\section{ACKNOWLEDGMENTS}

The authors gratefully acknowledge the financial support from the Hundred Talents Program of the Chinese Academy of Sciences, Liaoning Natural Science Foundation (Grant No. 201202218), the National Basic Research Program of China (Grant No. 2010CB631006), and the Major National Science and Technology Program of China (Grant No. 2011ZX02602).

\section{REFERENCES}

Bader, S., Gust, W. \& Hieber, H. (1995). Rapid formation of intermetallic compounds interdiffusion in the $\mathrm{Cu} / \mathrm{Sn}$ and $\mathrm{Ni} / \mathrm{Sn}$ systems. Acta Metall Mater 43(1), 329-337.

He, M., Chen, Z. \& QI, G. (2004). Solid state interfacial reaction of $\mathrm{Sn}-37 \mathrm{~Pb}$ and $\mathrm{Sn}-3.5 \mathrm{Ag}$ solders with Ni-P under bump metallization. Acta Mater 52, 2047-2056.

KIM, J.Y. \& YU, J. (2008a). Effects of residual impurities in electroplated $\mathrm{Cu}$ on the Kirkendall void formation during soldering. Appl Phys Lett 92, 092109.

Kim, J.Y. \& Yu, J. (2008b). Effects of residual S on Kirkendall void formation at $\mathrm{Cu} / \mathrm{Sn}-3.5 \mathrm{Ag}$ solder joints. Acta Mater 56, 5514-5523.

Laurila, T., Vuorinen, V. \& Kivilahti, J.K. (2005). Interfacial reactions between lead-free solders and common base materials. Mater Sci Eng R 49, 1-60.

Paul, A. (2004). The Kirkendall effect in solid state diffusion. Doctoral Dissertation, Technical University of Eindhoven Press.

Paul, A., van Dal, M.J.H., Kodentsov, A.A. \& van Loo, F.J.J. (2004). The Kirkendall effect in multiphase diffusion. Acta Mater 52, 623-630.

Peng, W., Monlevade, E. \& Marques, M.E. (2007). Effect of thermal aging on the interfacial structure of $\mathrm{SnAgCu}$ solder joints on Cu. Microelectron Reliab 47, 2161-2168.

Shang, P.J., Liu, Z.Q., LI, D.X. \& Shang, J.K. (2008). Bi-induced voids at the $\mathrm{Cu}_{3} \mathrm{Sn} / \mathrm{Cu}$ interface in eutectic $\mathrm{SnBi} / \mathrm{Cu}$ solder joints. Scripta Mater 58, 409-412.

Shang, P.J., Liu, Z.Q., Li, D.X. \& Shang, J.K. (2009a). TEM observations of the growth of intermetallic compounds at the SnBi/Cu interface. J Electron Mater 38, 2579-2584.

Shang, P.J., LiU, Z.Q., LI, D.X. \& Shang, J.K. (2011). Intermetallic compound identification and Kirkendall void formation in eutectic SnIn/Cu solder joint during solid-state aging. Phil Mag Lett 91, 410-417.

Shang, P.J., LiU, Z.Q., PANG, X.Y., Li, D.X. \& Shang, J.K. (2009b). Growth mechanisms of $\mathrm{Cu}_{3} \mathrm{Sn}$ on polycrystalline and single crystalline Cu substrates. Acta Mater 57, 4697-4706.

van Dal, M.J.H., Gusak, A.M., Cserhati, C., Kodentsov, A.A. \& VAN Loo, F.J.J. (2001). Microstructural stability of the Kirkendall plane in solid-state diffusion. Phys Rev Lett 86(15), 3353-3355.

Zeng, K., Stierman, R., Chiu, T.Z., Edwards, D., Ano, K. \& Tu, K.N. (2005). Kirkendall void formation in eutectic $\mathrm{SnPb}$ solder joints on bare $\mathrm{Cu}$ and its effect on joint reliability. J Appl Phys 97, 024508. 